\title{
Bioedusiana
}

http://jurnal.unsil.ac.id/index.php/bioed

DOI: https://doi.org/10.37058/bioed.v5i2.2246

Bioedusiana

\section{Peningkatan Self Regulation Mahasiswa melalui Strategi Perkuliahan "Students as Researchers" berbasis Online Learning}

\section{Improving Student Self Regulation through Online Learning-based "Students as Researchers" Lecture Strategy}

\author{
Febblina Daryanes ${ }^{1 *}$, Naila Fauza ${ }^{2}$ \\ 1,2 Program Studi Pendidikan Biologi, FKIP, Universitas Riau, Kampus Bina Widya J1. H.R Soebrantas \\ KM 12,5 Simpang Baru Panam, Pekanbaru 28293
}

\begin{abstract}
Abstrak
Kemampuan self regulation merupakan salah satu komponen penting dalam menentukan keberhasilan siswa. Hasil observasi menunjukkan bahwa masih banyak mahasiswa yang terlambat mengumpulkan tugas, tidak bisa mengikuti perkuliahan dengan baik, serta tidak jarang ditemui mahasiswa yang tidak siap saat presentasi. Ketidaksiapan tersebut dikarenakan mereka tidak bisa mengatur perencanaan diri secara efektif, hal tersebut menunjukkan bahwa masih rendahnya kemampuan self regulation mahasiswa. Tujuan penelitian ini yaitu untuk mengetahui peningkatan self regulation mahasiswa melalui strategi perkuliahan "Students as Researchers" berbasis online learning. Jenis penelitian ini adalah pre-eksperimen, dengan desain One-Group-Pretest-Posttes. Populasi pada penelitian ini yaitu seluruh mahasiswa pendidikan Biologi Universitas Riau. Sampel pada penelitian ini yaitu mahasiswa Pendidikan Biologi semester 3 (tiga) kelas A yang mengambil matakuliah Media Pembelajaran di Program Studi Pendidikan Biologi. Pengumpulan data dilakukan melalui angket self regulation awal dan akhir serta lembar observasi selama perkuliahan dengan menggunakan strategi "Students as Researchers" berbasis online learning. Angket self regulation telah diuji validitas dan reabilitasnya sebelum digunakan dalam penelitian. Analisis data penelitian menggunakan nilai normalisasi gain dan persentase ketercapaian kemampuan self regulation mahasiswa berdasarkan observasi. Hasil penelitian menunjukkan bahwa kemampuan self regulation mahasiswa setelah perkuliahan dengan strategi "Students as Researchers" berbasis online learning mengalami peningkatan dengan N-gain sebesar 0,71 dan berada dalam kategori tinggi. Indikator self regulation yang mengalami peningkatan paling tinggi yaitu mengatur rencana secara efektif. Kesimpulan penelitian ini yaitu kemampuan self regulation mahasiswa dapat ditingkatkan melalui strategi perkuliahan "Students as Researchers" berbasis online learning. Penelitian selanjutnya yang dapat dilakukan yaitu melihat aspek lain yang dapat ditingkatkan melalui strategi perkuliahan "Students as Researchers".
\end{abstract}

Kata kunci: Self Regulation; Students as Researchers; Online Learning

\begin{abstract}
Self-regulation ability is an important component in determining student success. The results of observations showed that there are still many students who are late in submitting assignments, cannot attend lectures properly, and it is not uncommon for students to encounter students who are not ready for presentation. This unpreparedness is because they cannot manage self-planning effectively, it shows that the students' self-regulation ability is still low. The purpose of this study was to determine the increase in student self regulation through "Students as Researchers" strategy with the online learning. This type of research is pre-experiment, with a OneGroup-Pretest-Posttest design. The population in this study were all students of Riau University Biology education. The sample in this study were students of Biology Education semester 3 (three) class A who took the Learning Media course in the Biology Education. Data collection was done via questionnaire self regulation early and late stage, and observation sheets during "Students as Researchers" strategy with online learning. The self-regulation questionnaire was tested for validity and reliability prior to use in this study. The analysis of research data is done by using the value of the normalization gain and the percentage of self regulation ability based on observation. The results showed that students' self-regulation abilities after implementation of "Students as Researchers" strategy with the online learning increased with an $N$-gain of 0.71 and was in the high category. The indicator of selfregulation that experienced the highest increase was managing plans effectively. The conclusion of this study is that the ability of student self-regulation can be improved through the "Students as Researchers" strategy with online learning. Further research that can be done is looking at other aspects that can be improved through the "Students as Researchers" strategy.
\end{abstract}

Keywords: Self Regulation; Students as Researchers; Online Learning 


\section{Article History}

Received: November, 17 $7^{\text {th }}$ 2020; Accepted: December, 27 $7^{\text {th }}$ 2020; Published: December, $31^{\text {st }} 2020$

Corresponding Author

Febblina Daryanes, Program Studi Pendidikan Biologi, FKIP Universitas Riau, E-mail: febblina.daryanes@lecturer.unri.ac.id

(C) 2020 Bioedusiana. This is an open access article under the CC BY-SA 4.0 license

(https://creativecommons.org/licenses/by-sa/4.0/)

\section{PENDAHULUAN}

Kebiasaan berpikir cerdas sangat penting dan telah dibahas secara luas oleh para peneliti. Self regulation merupakan salah satu indikator dari kebiasaan berpikir (habits of mind) (Marzano, 1994). Kegigihan dalam belajar dapat dilatih melalui pola pikir cerdas dan kemampuan self regulation para pelajar dalam memecahkan suatu permasalahan. Sejalan dengan hal tersebut, proses pembelajaran harus fokus pada transformasi pengalaman belajar melalui suatu strategi pembelajaran kognitif yang menantang dan memiliki kebebasan dalam memberdayakan pengaturan pemikiran sendiri (self regulation). Self regulation atau proses perilaku pengaturan diri meliputi pengaturan pemikiran dan tindakan seseorang serta meliputi tindakan fisik yang berguna untuk menyelesaikan tugas atau mencapai hal yang diinginkan (Zimmerman \& Schunk, 2011; Zimmerman, 2011).

Berdasarkan hasil observasi yang dilakukan menunjukkan bahwa masih banyak mahasiswa yang terlambat mengumpulkan tugas, tidak bisa mengikuti perkuliahan dengan baik, serta tidak jarang ditemui mahasiswa yang tidak siap saat presentasi, ketidaksiapan tersebut dikarenakan mereka tidak bisa mengatur perencanaan diri secara efektif, hal tersebut menunjukkan bahwa masih rendahnya kemampuan self regulation mahasiswa. Pada dasarnya setiap manusia memiliki kemampuan self regulation pada tingkatannya masing-masing, tetapi untuk mencapai kinerja yang baik perlu dikembangkan keterampilan pemantauan strategi belajar yang efektif, selain itu perlu adanya strategi pembelajaran yang menekankan pada pembentukan dan pengembangan kemampuan self regulation. Beberapa penelitian (Basso \& Abrahao, 2018; Vrielin, et al., 2018) menunjukkan bahwa kemampuan self regulation dapat dilatih dan ditingkatkan.

Self regulation dibutuhkan saat seseorang belajar mandiri, bagaimana seseorang tersebut dapat merencanakan, memantau dan mengevaluasi secara efektif strategi belajar yang mereka lakukan (Basso \& Abrahao, 2018). Kemampuan self regulation merupakan salah satu komponen penting dalam menentukan keberhasilan siswa, penelitian yang dilakukan oleh Wandler \& Imbriale (2017) menyatakan bahwa strategi self regulation yang baik akan memberikan dampak positif terhadap prestasi akademik. Sejalan dengan hal tersebut menurut Mirhosseini (2018) strategi self regulation dapat meningkatkan motivasi, kinerja akademik dan self-efficacy siswa bahkan menurut penelitian Göy (2017) melalui strategi self regulation dapat meningkatkan kemampuan menulis.

Penelitian Alhamlan et al., (2018) menyatakan bahwa kerangka pembelajaran student 
centered learning akan melatih siswa secara kritis merefleksikan bagaimana mereka mengatur jalan pikiran mereka. Strategi pembelajaran "Students as Researchers" merupakan salah satu strategi pembelajaran yang berorientasi pada pendekatan "student centered learning" dan dapat melatih serta meningkatkan kemampuan self regulation mahasiswa. Strategi pembelajaran tersebut akan melibatkan mahasiswa secara penuh dalam menggali dan menemukan konsep materi serta melakukan secara langsung sebuah penelitian yang telah dirancang agar mahasiswa mendapatkan pengalaman yang bermakna. Strategi perkuliahan "Students as Researchers", pada kapasitasnya memungkinkan siswa untuk merefleksikan kondisi mengajar dan belajar berkaitan dengan masyarakat belajar dan pembelajaran seumur hidup (Fielding \& Bragg, 2003).

Melalui kemampuan self regulation yang baik, seseorang secara aktif menciptakan strategi, sasaran, dan makna dari sebuah perencanan efektif. Pelajar dapat mengatur diri sendiri, menyadari kendala, konteks serta dapat memantau tindakan mereka. Pelajar dapat menetapkan tujuan atau standar untuk menilai ketepatan strategi pembelajaran atau perlu merubahnya. Melalui kemampuan self regulation pelajar dapat memediasi pengaruh konteks eksternal dan karakteristik personal sehingga dapat meningkatkan prestasi akademik dan kinerjanya (Ozan et al., 2012).

Pendidikan di Indonesia harus dapat memanfaatkan perkembangan teknologi untuk mendukung proses pembelajaran yang positif. Ada beberapa manfaat pembelajaran yang didukung melalui teknologi (pembelajaran online) diantaranya pembelajaran lebih fleksibel, memungkinkan pembelajaran terjadi pada jarak jauh, dan memungkinkan pendidik dan mahasiswa dapat meninjau dan mempelajari konten materi secara cepat, mudah, kapan saja dan dimana saja mereka berada (Alsalhi, et al., 2019). Saat ini Indonesia sedang mengalami pandemi Covid-19, sejak virus ini masuk ke Indonesia, pemerintah mulai mengeluarkan surat edaran untuk tidak melakukan kegiatan dalam keramaian dan menerapkan social distancing. Salah satu dampaknya yaitu sekolah dan perguruan tinggi harus melakukan pembelajaran secara online.

Beberapa penelitian yang pernah dilakukan terkait kemampuan self regulation diantaranya yang dilakukan oleh Ganda \& Boruchovitch (2018), hasil penelitiannya menunjukkan bahwa Program "Self Regulated Learning" meningkatkan self regulation siswa. Penelitian yang dilakukan oleh Basso \& Abrahao (2018) menunjukkan bahwa pembelajaran interdisipliner memberikan peluang yang lebih besar dalam mengembangkan kemampuan self regulation siswa. Penelitian yang dilakukan oleh Wandler \& Imbriale (2017), mengatakan bahwa pembelajaran mandiri yang menekankan pada self regulation siswa melalui kursus online memberikan dampak positif terhadap prestasi akademik siswa. Belum ada penelitian yang membahas secara spesifik mengenai strategi "Students as Researchers" dalam meningkatkan kemampuan self regulation mahasiswa.

Berdasarkan ulasan di atas dan untuk pencapaian salah satu Misi Fakultas Keguruan dan 
Ilmu Pendidikan Universitas Riau yaitu, "Melaksanakan pendidikan dan pengajaran yang berorientasi riset dengan sistem pembelajaran online atau Online Learning", maka peneliti tertarik untuk melakukan penelitian dengan judul "Peningkatan Self Regulation Mahasiswa melalui strategi "Students as Researchers" berbasis Online Learning.

Penelitian ini bertujuan untuk meningkatkan kemampuan self regulation mahasiswa melalui strategi perkuliahan "Students as Researchers" berbasis Online Learning. Penelitian ini memberikan sumbangsih ide strategi perkuliahan yang dapat dikembangkan untuk melatih kemampuan self regulation mahasiswa, melatih kemampuan dan keterampilan mahasiswa untuk memanfaatkan teknologi dalam pembelajaran serta mengembangkan jiwa mahasiswa sebagai peneliti.

\section{METODE}

Populasi pada penelitian ini yaitu seluruh mahasiswa pendidikan Biologi Universitas Riau. Sampel pada penelitian ini yaitu mahasiswa Pendidikan Biologi semester 3 (tiga) kelas A yang mengambil matakuliah Media Pembelajaran di Program Studi Pendidikan Biologi. Teknik pengambilan sampel melalui purposive sampling. Penelitian ini merupakan pre-eksperimen dan menggunakan analisis data kuantitatif. Desain penelitian yang digunakan adalah One-GroupPretest-Posttest, desain ini digunakan untuk membandingkan pretest dan posttes pada kelompok uji coba, dilakukan dua kali tes yaitu sebelum kelas diberi perlakuan (pretest) dan sesudah kelas mendapat perlakuan (posttest) (Fraenkel \& Wallen, 2012). Perlakuan pada penelitian ini dengan penerapan strategi perkuliahan "Students as Researchers" berbasis Online Learning. Sumber data dalam penelitian adalah sumber primer yaitu mahasiswa. Menurut Sugiyono (2014), data primer merupakan data yang dikumpulkan sendiri oleh peneliti langsung dari sumber pertama atau tempat objek penelitian dilakukan. Desain penelitian disajikan pada table 1 sebagai berikut:

Tabel 1. Desain penelitian

\begin{tabular}{cclc}
\hline Kelompok & Pretest & Perlakuan & Posttest \\
\hline $\mathbf{E}$ & $\mathrm{O}_{1}$ & $\mathrm{X}_{\mathrm{SAR}+\text { Online L. }}$ & $\mathrm{O}_{2}$ \\
\hline
\end{tabular}

$\begin{array}{ll}\text { Keterangan } & : \\ \mathrm{E} & : \text { Kelompok Eksperimen } \\ \mathrm{O}_{1} & : \text { Pemberian Pretest } \\ \mathrm{X}_{\mathrm{SAR}+\mathrm{OL}} & : \text { Pembelajaran "Students as Researchers" berbasis Online Learning } \\ \mathrm{O}_{2} & : \text { Pemberian Posttest }\end{array}$


Data penelitian ini diperoleh dari Angket penelusuran Self Regulation (Marzano, 1994) modifikasi, angket diberikan pada saat sebelum dan sesudah perkuliahan dengan menggunakan strategi "Students as Researchers" berbasis Online Learning, angket bertujuan untuk mendeskripsikan kemampuan self regulation mahasiswa sebelum dan sesudah penerapan strategi perkuliahan "Students as Researchers" berbasis Online Learning. Lembar observasi yang dikembang dari Sriyati (2011), bertujuan untuk mendeskripsikan keterlaksanaan proses perkuliahan "Students as Researchers" dengan menekankan jabaran indikator self regulation mahasiswa yang terdiri dari 1) menyadari pemikiran sendiri, 2) membuat rencana efektif, 3) menggunakan sumber-sumber informasi yang dibutuhkan, 4) sensitif terhadap umpan balik, 5) mengevaluasi tindakan. Lembar observasi digunakan selama proses perkuliahan dengan menggunakan strategi "Students as Researchers". Melalui lembar observasi akan terlihat bagaimana perkembangan kemampuan self regulation mahasiswa. Sebelum instrumen digunakan dalam penelitian, maka dilakukan uji validitas dan reabilitas instrument. Setelah itu, data dianalisis secara kuantitatif untuk mengetahui tingkat validitas dan reliabilitas instrumen. Data yang diperoleh sebelumnya berdasarkan angket self regulation dalam bentuk data ordinal dikonfersi terlebih dahulu melalui MSI sehingga diperoleh data dalam bentuk data interval, setelah itu dilakukan uji prasyarat terlebih dahulu, yaitu uji normalitas. Uji normalitas data dilakukan untuk mengetahui apakah data yang diperoleh dari populasi yang berdistribusi normal atau tidak. Uji normalitas dihitung melalui Program SPSS. Setelah itu dilanjutkan uji signifikansi menggunakan uji parametric Paired Sample T-Test, data yang diperoleh dari data angket self regulation mahasiswa diawal (pretest) dan diakhir (posttest) akan digunakan untuk mencari nilai N-gain. Nilai N-gain berfungsi untuk mengetahui seberapa besar peningkatan self regulation mahasiswa setelah mengikuti pembelajaran dengan strategi perkuliahan "Students as Researchers" berbasis Online Learning. Untuk mendapatkan nilai N-gain maka akan digunakan rumus sebagai berikut (Meltzer, 2002):

$$
\mathrm{N}-\mathrm{Gain} / \text { Indeks Gain }=\frac{\text { skor posttest }- \text { skor pretest }}{\text { skor maksimal-skorpretest }}
$$

$\mathrm{N}$-gain/indeks gain yang diperoleh (pretest dan posttest) menunjukkan kategori peningkatan self regulation mahasiswa. Kategori tersebut dapat dilihat dalam Tabel 2 berikut (Meltzer, 2002).

Tabel 2. Kategorisasi Skor N-gain/Indeks Gain

\begin{tabular}{cc}
\hline Rentang & Kategori \\
\hline $0,70-1,00$ & Tinggi \\
$0,31-0,69$ & Sedang \\
$0-0,30$ & Rendah \\
\hline
\end{tabular}

Data observasi kelas yang tercantum pada lembar observasi selama perkuliahan dengan strategi "Students as Researchers" berbasis Online Learning dianalisis dengan cara dihitung persentasenya. Berdasarkan data tersebut diketahui ketercapaian self regulation mahasiswa yang 
dilatihkan setiap kali pembelajaran dengan menggunakan strategi perkuliahan "Students as Researchers" berbasis Online Learning. Kriteria dari persentase nilai (Purwanto, 2009) yang diperoleh dapat dilihat pada Tabel 3 berikut:

Tabel 3. Kategorisasi Hasil Persentase Lembar observasi

\begin{tabular}{cc}
\hline Ketercapaian & Kategori \\
\hline $86-100 \%$ & Baik Sekali \\
$76-85 \%$ & Baik \\
$60-75 \%$ & Cukup \\
$55-59 \%$ & Kurang \\
$\leq 54 \%$ & Kurang Sekali \\
\hline
\end{tabular}

\section{HASIL DAN PEMBAHASAN}

Peningkatan Indikator self regulation terhadap strategi perkuliahan "Students as Researchers" berbasis Online Learning

Menurut Marzano, et al., (1994), indikator self regulation terdiri dari (1) menyadari pemikirannya sendiri, (2) membuat rencana secara efektif, (3) menyadari dan menggunakan sumber-sumber informasi yang diperlukan, (4) sensitif terhadap umpan balik, (5) mengevaluasi keefektifan tindakan. Hasil data angket self regulation berupa data ordinal dikonversi terlebih dahulu menjadi data interval melalui MSI. Peningkatan kategori self regulation dianalisis melalui uji signifikansi, sebelumnya terlebih dahulu dilakukan uji normalitas sebagai uji prasyarat. Uji normalitas menggunakan uji Kolmogrov Sminov. Data dikatakan berdistribusi normal jika nilai Asymp. Sig $>\frac{1}{2} \alpha(0,025)$, dan jika nilai Asymp. Sig $<\frac{1}{2} \alpha(0,025)$ maka data tidak berdistribusi normal. Hasil olah data uji normalitas dari skor angket self regulation sebelum (pretest) dan sesudah (posttest) penerapan strategi "Students as Reserachers" memiliki nilai Asymp. Sig sebesar 0,152 dan 0,048 Hal tersebut menunjukkan data terdistribusi normal. Sehingga dilanjutkan uji signifikansi menggunakan uji parametrik Paired Sample T-Test, dan diperoleh hasil nilai Sig. (2tailed $)<\frac{1}{2} \alpha(0,025)$ yaitu sebesar 0,000 hal tersebut menunjukkan bahwa terdapat perbedaan yang signifikan antara rerata skor angket self regulation sebelum dan sesudah penerapan perkuliahan dengan strategi "Students as Reserchers" berbasis online learning. Rerata skor awal, skor akhir serta N-gain untuk tiap indikator self regulation disajikan pada Gambar 1. 


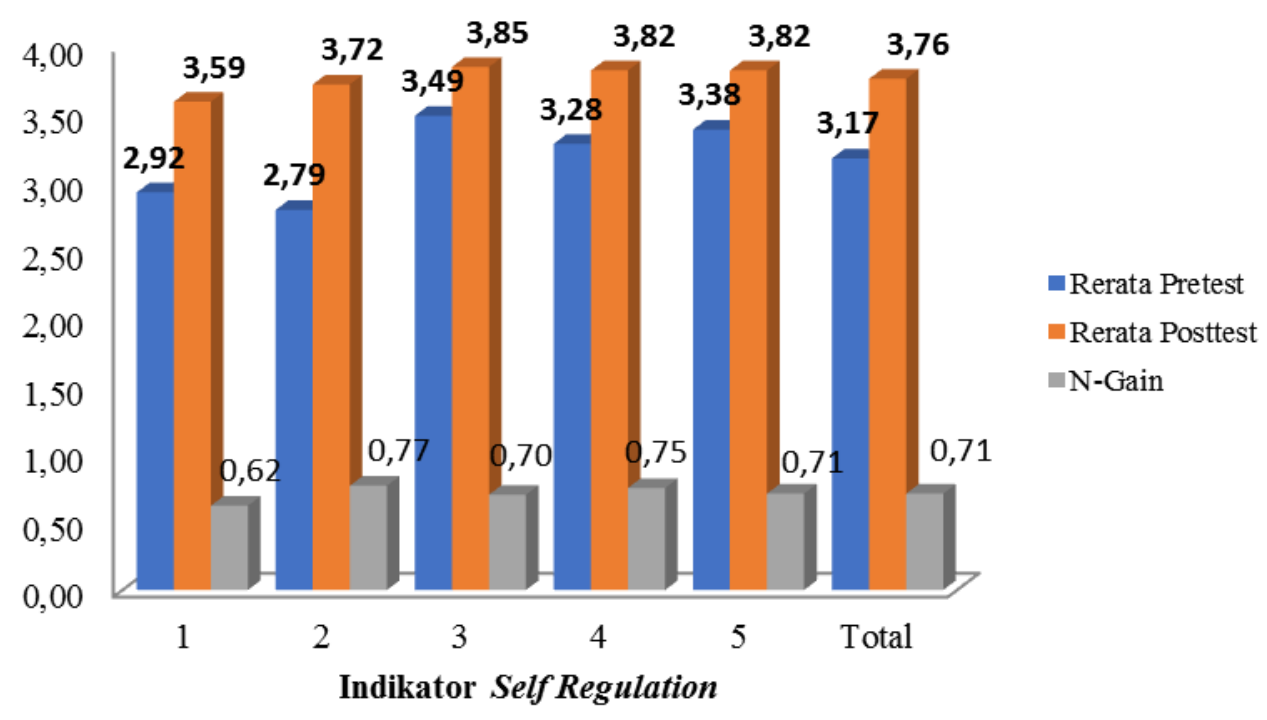

Gambar 1. Rerata Skor Awal, Skor Akhir, dan N-gain Self Regulation: (1) menyadari pemikirannya sendiri, (2) membuat rencana secara efektif, (3) menyadari dan menggunakan sumber-sumber informasi yang diperlukan, (4) sensitif terhadap umpan balik, (5) mengevaluasi keefektifan tindakan.

Berdasarkan hasil analisis data yang telah diperoleh, melalui strategi perkuliahan "Students as Researchers" berbasis Online Learning terhadap kemampuan self regulation mahasiswa mengalami peningkatan dengan nilai $\mathrm{N}$-gain total sebesar 0,71 berada dalam kategori tinggi. Pada proses perkuliahan dengan menggunakan strategi "Students as Researchers" mahasiswa dilatih untuk melakukan penelitian pengembangan sebuah produk media pembelajaran sederhana pada matapelajaran Biologi atau IPA SMP. Adapun tahapan kegiatan yang dilakukan mahasiswa melalui strategi perkuliahan "Students as Researchers" pada penelitian ini yaitu (1) Analisis kebutuhan (Analysis) terhadap pengembangan media pembelajaran sederhana yang dilakukan di satuan pendidikan tertentu secara online, (2) Mendesain media pembelajaran sederhana (Design), (3) Mengembangkan media pembelajatan sederhana (Development), (4) Membuat video pembelajaran dengan menggunakan media sederhana yang telah dikembangkan (Implementation), (5) Mengevaluasi media pembelajaran sederhana yang sudah dibuat (Evaluation). Untuk selanjutnya akan dibahas secara rinci tahapan perkuliahan "Student as Researchers" berbasis Online Learning.

Setiap proses kegiatan pada strategi perkuliahan yang telah dilakukan membuat mahasiswa mendapatkan pengalaman sebagai peneliti. Mereka mengembangkan sebuah produk media pembelajaran sederhana dengan tahapan ilmiah sehingga akan memperkaya ilmu pengetahuan mereka seperti yang dikemukakan oleh Harland, (2016), mengajar harus membuat mahasiswa sebagai peneliti "sampai pada sasaran" dan jika ini dapat dicapai, maka tujuan pun akan dapat dicapai dengan baik. Strategi perkuliahan "Student as Researchers" ini melatih bagaimana mahasiswa dapat bekerja dalam berbagai disiplin ilmu terutama di zaman modern seperti saat ini. Salah satu pendekatan dalam perkuliahan yang potensial untuk memfasilitasi 
penelitian dalam mengajar mahasiswa sebagai peneliti dalam komunitas pengetahuan yaitu menggunakan proses atau langkah-langkah yang sama yang digunakan oleh peneliti berpengalaman sebagai proses pembelajaran dan pengembangan diri mahasiswa. Lillywhite \& Wolbring (2019) juga mengemukakan bahwa pengalaman penelitian bermanfaat bagi mahasiswa karena dapat meningkatkan tingkat kelulusan dan disiplin ilmu pada pendidikan Sains, Teknologi, Teknik, dan Matematika (STEM).

Menurut Harland (2016), bahwa jika mahasiswa belajar sebagai peneliti maka akan membuat hasil pendidikan menjadi lebih baik, mereka terlibat dalam aktifitas pengembangan kemampuan pengaturan diri mereka sehingga memiliki rasa tanggungjawab. Melalui aktifitas tersebut mereka terlibat dalam penelitian sebagai individu, berkolaborasi dengan teman, guru, hingga komunitas lainnya. Mahasiswa sebagai peneliti akan melatih mereka untuk mengembangkan kemampuan dirinya. Mahasiswa menyeimbangkan informasi dengan interaksi yang dilakukannya sebagai upaya untuk mencapai tujuan. Melalui tahapan-tahapan penelitian yang telah dilakukan mahasiswa sebagai peneliti memiliki peluang untuk mengartikulasikan pemikiran mereka tentang alasan dan keputusan mereka mengembangkan suatu media pembelajaran sederhana yang telah mereka buat dalam penelitiannya dan mereka akan lebih menyadari pemikiran mereka sendiri.

Berdasarkan Gambar 1, menunjukkan bahwa indikator 2 "membuat rencana secara efektif" yang merupakan salah satu indikator ketercapaian dari self regulation memiliki nilai Ngain tertinggi yaitu sebesar 0,77 berada pada kategori tinggi. Selama pembelajaran dengan menggunakan strategi perkuliahan "Students as Researchers", dosen menfasilitasi mahasiswa untuk bisa mengeksplore pengetahuannya secara mandiri. Mahasiswa terlebih dahulu melakukan tahapan penelitian pengembangan yaitu melakukan analisis kebutuhan (Analysis) dalam pengembangan media pembelajaran sederhana, tahapan ini melatih mahasiswa dalam menyadari pemikirannya sendiri dan menyusun rencana secara efektif, mahasiswa harus menyusun pertanyaan-pertanyaan yang menuntun untuk mendapatkan informasi yang komprehensif dalam mengetahui keadaan dan kebutuhan pada situasi nyata sehingga dapat mengembangkan media pembelajaran sederhana sesuai dengan yang dibutuhkan, hal tersebut akan membantu mereka membuat rencana secara rinci dan efektif agar tercapai tujuan yang hendak dicapai.

Selain itu, tahapan analisis kebutuhan juga melatih mahasiswa untuk senantiasa mencari berbagai macam sumber informasi melalui wawancara ataupun observasi. Pengalaman siswa dalam menghasilkan sesuatu akan menguraikan perubahan dalam praktik dan bermanfaat untuk belajar, mengajar dan memimpin. Sebuah praktik berbasis bukti akan menghasilkan pengetahuan baru (Ryerson, 2017). Dalam strategi perkuliahan "Students as Researchers" merupakan suatu praktik berbasis bukti dan hal-hal yang valid, maka dari itu tentunya akan 
melatih mahasiswa untuk mengatur rencananya serta keefektifan tindakannya untuk menghasilkan produk yang layak dan valid. Selain itu, tahapan pada strategi "Students as Researchers" juga menfasilitasi mahasiswa untuk menghasilkan hal-hal yang valid. Saat proses pembelajaran yang melibatkan siswa sebagai peneliti, maka siswa dituntut untuk melakukan kolaborasi dengan lingkungan, orang lain dan masyarakat sehingga hal tersebut memberikan manfaat bagi siswa (Ryerson, 2017), seperti yang telah dilakukan oleh mahasiswa, mereka melakukan analisis kebutuhan dengan mewawancarai langsung seorang guru pada satuan pendidikan tertentu, hal tersebut melatih mereka untuk mengatur rencana secara efektif dalam menyusun rincian setiap tahap pertanyaan yang akan diajukan. Selain itu, bermanfaat dalam membangun hubungan satu dengan lainnya dalam menumbuhkan pemikiran kritis dan menambah pengalaman siswa untuk membangun profesionalitasnya dalam pembelajaran dan membangun pemahaman serta apresiasi masyarakat. Kegiatan mewawancarai guru pada satuan pendidikan dilakukan secara online sehingga mahasiswa bebas mewawancarai guru pada sekolah manapun, proses yang dilakukan juga menjadi lebih cepat karena mereka memiliki waktu yang fleksibel. Kegiatan analisis kebutuhan berbasis online tersebut tentunya menguntungkan mahasiswa dan guru juga tidak merasa terbebani dikarenakan kegiatan wawancara mereka lebih santai dan tidak dibatasi jam kerja.

Tahapan mendesain media pembelajaran sederhana (design) dapat melatih kemampuan menyusun rencana secara efektif, mahasiswa akan merinci terlebih dahulu tahapan-tahapan untuk membuat media sederhana, dimulai dengan menentukan media sederhana yang hendak dibuat yang sesuai dengan karakteristik siswa yang berdasarkan dari kegiatan analisis kebutuhan, kemudian mahasiswa mulai merinci alat dan bahan yang diperlukan untuk merakit media sederhana tersebut serta melatih kemampuan membuat rencana secara efisien dalam penggunaan biaya untuk mengembangkan media pembelajaran sederhana yang kreatif dan inovatif.

Pada tahapan pengembangan (development), mahasiswa mulai mengembangkan media pembelajaran sederhanan, mereka mulai mengatur jadwal untuk mengerjakan setiap tahapan dalam membuat media pembelajaran sederhana tersebut, hal itu tentu melatih mahasiswa dalam mengembangkan kemampuan pengaturan rencana secara efektif agar pembuatan media pembelajaran dapat selesai tepat waktu dan sesuai dengan tujuan yang akan dicapai. Pada tahap merancang dan mengembangkan media pembelajaran dilakukan secara online. Mahasiswa bisa menghubungi dosen via whatsapp, telpon, ataupun melalui googleclassroom sehingga mahasiswa bisa berdiskusi secara intensif mengenai media yang akan dikembangkan, setiap mahasiswa memiliki peluang yang besar untuk bisa berkomunikasi dengan dosen melalui pembelajaran berbasis online. 
Berdasarkan data hasil penelitian pada Gambar 1., indikator "sensitif terhadap umpan balik" merupakan indikator pencapaian self regulation yang memiliki nilai N-Gain tertinggi setelah indikator "membuat rencana secara efektif", yaitu sebesar 0,75 berada pada kategori tinggi. Menurut (Ryerson, 2017) bahwa strategi pembelajaran seorang siswa menjadi peneliti akan meningkatkan pengaturan diri mereka. Dampak yang terlihat diantaranya, kemampuan berinteraksi, dan penilaian diri sendiri meliputi evaluasi dan refleksi. Kegiatan menvalidasi media yang telah dikembangkan membuat mahasiswa mengetahui kekurangan dan kelebihan yang ada pada media yang telah dikembangkan berdasarkan penilaian dari validator, hal tersebut melatih kemampuan "sensitif terhadap umpan balik", kemudian mahasiswa akan memperbaiki media pembelajaran tersebut sebelum digunakan dalam proses pembelajaran, maka kemampuan "mengevaluasi tindakan" akan terlatih pada proses tersebut.

Pada tahapan implementasi (Implementation), mahasiswa membuat video pembelajaran dengan menggunakan media sederhana yang telah dikembangkan lalu melakukan sharing session video pembelajaran pada akun youtube, hal ini juga memudahkan guru sebagai validator untuk memberikan saran, selain itu melalui video pembelajaran yang dishare melalui akun youtube mendapatkan lebih banyak saran masukkan dikarenakan akses yang tidak terbatas. Hal ini merupakan kelebihan dari strategi perkuliahan berbasis online learning. Selain itu, mahasiswa akan lebih terlatih menggunakan teknologi informasi dalam proses pembelajaran yang merupakan tuntutan dalam menghadapi kemajuan zaman saat ini.

Pada tahapan evaluasi (Evaluation), mahasiswa juga dilatih untuk dapat sensitif terhadap umpan balik serta dapat mengevaluasi tindakan untuk dapat menghasilkan media pembelajaran yang lebih baik lagi, mahasiswa akan terbiasa selalu melakukan refleksi terhadap segala kegiatan yang dilakukan. Secara keseluruhan proses pembelajaran dengan menggunakan strategi perkuliahan "Students as Researchers" membantu mahasiswa meningkatkan kemampuan self regulation. Sesuai yang dikemukakan oleh Peseta et al., (2016), strategi perkuliahan "Students as Researchers" merupakan suatu pendekatan yang memberikan peluang untuk peningkatan kemampuan inkuiri mahasiswa. Tahapan strategi tersebut memberikan kesempatan mahasiswa untuk berdialog dan berinteraksi dengan orang lain, belajar dari praktik interdisipliner, ikut serta dalam menghasilkan sesuatu serta selalu merefleksi diri. Melalui pembelajaran online, hasil dokumentasi rancangan dan produk media sederhana yang dikembangkan dikumpulkan melalui googleclasroom, sehingga dosen dengan mudah mengoreksi kerja mahasiswa satu persatu karena tugas-tugas mahasiswa sudah terorganisir dengan baik. Hal tersebut akan membuat setiap mahasiswa mengetahui saran perbaikan tentang media yang mereka kembangkan.

Mahasiswa membutuhkan kesempatan untuk menilai sendiri dan secara aktif terlibat serta bertindak berdasarkan umpan balik terhadap kerja mereka untuk mendapatkan manfaat dari sebuah pembelajaran. Saat ini, harus disadari bahwa pembelajaran yang sebenarnya berasal 
dari bagaimana siswa dapat memperbaiki hasil kerjanya berdasarkan umpan balik untuk meningkatkan performa dan pengetahuannya. Strategi perkuliahan "Students as Researchers" ini juga membuat mahasiswa menjadi mengerti dan termotivasi untuk mencari peluang dalam melakukan penelitian skripsinya kelak. Saat kemampuan self regulation mahasiswa meningkat maka motivasi merekapun akan meningkat hal ini akan mendukung proses belajar, hal tersebut sejalan dengan yang dikemukakan oleh Mirhosseini (2018), bahwa jika seseorang memiliki kemampuan pengaturan dirinya, maka akan meningkatkan motivasi yang merupakan hal penting untuk belajar. Berdasarkan temuan Güryay (2016) juga menyatakan bahwa peserta didik dengan pengaturan diri yang baik akan termotivasi secara akademik dan menunjukkan pembelajaran yang lebih berkualitas.

\section{Hasil observasi selama kegiatan perkuliahan "Students as Researchers" berbasis online learning}

Berdasarkan hasil lembar observasi selama perkuliahan strategi "Students as Researchers" diperoleh hasil rerata kemampuan self regulation mahasiswa pada setiap indikator. Adapun ketercapaian kemampuan self regulation mahasiswa pada setiap indikator dapat dilihat pada Gambar 2 berikut:

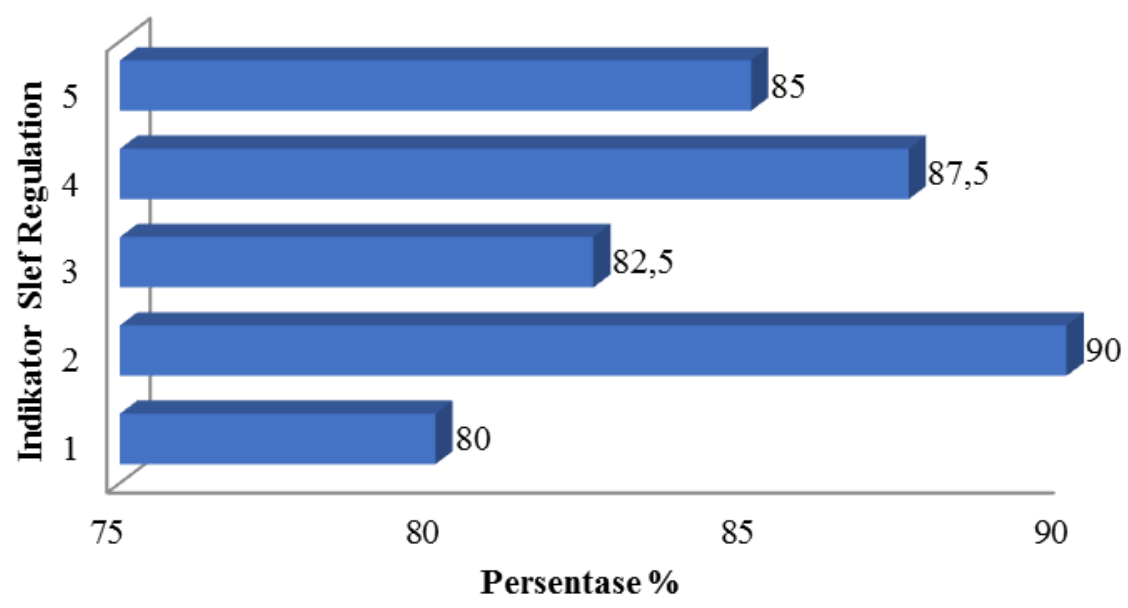

Gambar 2. Hasil observasi ketercapaian kemampuan selfregulation mahasiswa selama perkuliahan

"Students as Researchers" berbasis online learning: (1) menyadari pemikirannya sendiri, (2) membuat rencana secara efektif, (3) menyadari dan menggunakan sumber-sumber informasi yang diperlukan, (4) sensitif terhadap umpan balik, (5) mengevaluasi keefektifan tindakan

Berdasarkan Gambar 2 tersebut, dapat diketahui bahwa kemampuan self regulation mahasiswa pada setiap indikator selama perkuliahan dengan strategi "Students as Researchers" berada pada kategori baik dan sangat baik, hasil tersebut sesuai dengan hasil angket mahasiswa bahwa melalui perkuliahan dengan strategi "Students as Researchers" dapat meningkatkan kemampuan self regulation mahasiswa.

Berdasarkan hasil observasi, terlihat bahwa ketercapaian indikator "mengatur rencana secara efektif" sebesar 90\% berada pada kategori sangat baik, hal ini sesuai dengan hasil angket 
mahasiswa. Selama perkuliahan dengan strategi "Students as Researchers", mahasiswa dilatih untuk mengembangkan kemampuan "mengatur rencana secara efektif" secara bertahap semakin lama membuat mahasiswa semakin memperhatikan setiap rencana, strategi dan perilakunya agar dapat bertindak secara efektif. Biasanya mahasiswa hanya mengerjakan tugas yang diberikan oleh dosen, tetapi pada strategi perkuliahan "Students as Researchers" mahasiswa dilatih untuk merancang sebuah produk yang mereka rencanakan sendiri dengan berlandaskan pada analisis kebutuhan yang mereka lakukan. Setiap tahapan juga akan menentukan hasil pada tahapan selanjutnya karena mahasiswa melakukan rangkaian kegiatan yang saling berkaitan dan memiliki dasar pemikiran untuk mengembangkan kegiatan selanjutnya, hal tersebut membuat mahasiswa harus dapat membuat rencana secara efektif agar setiap tahapan dapat dilakukan dan produk yang dihasilkan menjadi lebih baik. Sejalan dengan penelitian yang dilakukan oleh Peseta et al., (2016), bahwa strategi siswa sebagai peneliti dirancang untuk perluasan kemandirian serta melatih kemampuan inkuiri siswa sehingga memberikan kesempatan yang sebesar-besarnya untuk siswa mengatur strategi secara efektif dalam menyelesaikan suatu produk atau menghadapi permasalahan yang ditemuinya.

Pada indikator "menyadari dan menggunakan sumber-sumber informasi yang diperlukan" terlihat adanya peningkatan pada setiap pertemuan. Mahasiswa sudah menggunakan berbagai sumber informasi baik dari hasil wawancara, kajian literatur dari berbagai referensi, jurnal-jurnal penelitian terkait pengembangan media pembelajaran hingga browsing internet (youtube) untuk mencari ide-ide kreatif dalam mengembangkan media pembelajaran sederhana. Mahasiswa bahkan meminta referensi tambahan dari sumber buku yang dimiliki oleh dosen. Mahasiswa menyadari bahwa untuk menghasilkan media pembelajaran yang efektif, efisien dan bermutu perlu menggali berbagai sumber-sumber informasi. Hal tersebut seperti yang dikemukakan oleh Lillywhite \& Wolbring (2019), bahwa saat siswa berperan sebagai penghasil pengetahuan yaitu sebagai peneliti maka hal tersebut dapat menginspirasi kreativitas, keterbukaan pemikiran, berpikir kritis dan senantiasa menggali berbagai sumber informasi yang relevan.

Mahasiswa juga selalu mengevaluasi media sederhana yang mereka kembangkan, mulai dari merancang desain, membuat, hingga menyebarkan penggunaan media sederhana mereka dalam bentuk video pembelajaran. Terlihat mahasiswa selalu memperbaiki produk yang mereka hasilkan, hingga hasil akhir produk mereka merupakan media sederhana yang komplit dan kreatif, dari yang semula mereka hanya merancang sebuah produk untuk media ajar hingga mereka mengembangkannya juga sebagai media evaluasi pembelajaran dalam bentuk games. Kegiatan diskusi, presentasi, serta evaluasi dari dosen dan teman sejawat juga memberikan kesempatan kepada mahasiswa untuk meningkatkan kemampuan mereka agar lebih sensitif terhadap umpan balik dan melakukan refleksi atas media sederhana mereka. Hal tersebut sejalan 
dengan yang dikemukakan oleh Ryerson (2017), bahwa melalui strategi "siswa sebagai peneliti" membuat siswa terlibat dalam refleksi berulang tentang pengalaman yang telah mereka lakukan. Peseta et al., (2016) juga mengemukakan bahwa strategi "siswa sebagai peneliti" memberikan kesempatan untuk berdialog, belajar berbasis praktik, dan refleksi.

\section{SIMPULAN}

Secara keseluruhan kemampuan self regulation mahasiswa mengalami peningkatan dalam kategori tinggi setelah mengikuti pembelajaran dengan strategi perkuliahan "Student as Reseachers" berbasis online learning. Indikator menyusun "rencana secara efektif" merupakan indikator yang mengalami peningkatan paling tinggi dibandingkan indikator self regulation lainnya. Berdasarkan hasil observasi, kemampuan self regulation mahasiswa terus meningkat pada setiap pertemuan, pembelajaran secara online juga mendukung mahasiswa dalam mengembangkan kemampuan self regulation.

\section{UCAPAN TERIMA KASIH}

Penulis mengucapkan terimakasih kepada Pihak Universitas Riau dan Fakultas Keguruan dan Ilmu Pendidikan yang telah mendanai penelitian ini, Dosen tim teaching matakuliah media pembelajaran, serta berbagai pihak yang telah membantu dan mendukung pelaksanaan penelitian ini.

\section{REFERENSI}

Alhamlan, S., Aljasser, H., Almajed, A., Almansour, H., \& Alahmad, N. (2018). A Systematic Review: Using Habits of Mind to Improve Student's thinking in Class. Higher Education Studies, 8(1), 25. https://doi.org/10.5539/hes.v8n1p25

Alsalhi, N. R., Eltahir, M. E., \& Al-Qatawneh, S. S. (2019). The effect of blended learning on the achievement of ninth grade students in science and their attitudes towards its use. Heliyon, 5(9), e02424. https://doi.org/10.1016/j.heliyon.2019.e02424

Basso, Fabiane Puntel, Abrahao, M. H. M. . (2018). Teaching Activities that Develop Learning Self-Regulation. Educação \& Realidade, 43(2), 495-511. https://doi.org/http://dx.doi.org/10.1590/2175-623665212

Fielding, M., \& Bragg, S. (2003). Students as Researchers Making a Difference. Chesterton Mill, French's Road, Cambridge: Pearson Publishing.

Fraenkel \& Wallen. (2012). How to Design and Evaluate research in education. New York: Mc Graw Hill.

Ganda, D. R., \& Boruchovitch, E. (2018). Promoting Self-regulated Learning of Brazilian Preservice Student Teachers: Results of an Intervention Program. Frontiers in Education, 3(February), 1-12. https://doi.org/10.3389/feduc.2018.00005

Göy, N. (2017). An Action Research on the Development of Self-regulated Writing Strategies of Turkish EFL Students. Eurasian Journal of Applied Linguistics, 3(2), 191- 
204.

Güryay, B. (2016). The Relationship between Learning Modalities and Perceived Self-regulation Levels. Procedia - Social and Behavioral Sciences, 232(April), 389-395. https://doi.org/10.1016/j.sbspro.2016.10.054

Harland, T. (2016). Teaching to enhance research. Higher Education Research and Development, 35(3), 461-472. https://doi.org/10.1080/07294360.2015.1107876

Lillywhite, A., \& Wolbring, G. (2019). Undergraduate disabled students as knowledge producers including researchers: A missed topic in academic literature. Education Sciences, 9(4), 1-21. https://doi.org/10.3390/educsci9040259

Marzano, R.J., (1994). Assesing students outcomes; performance assessment using the dimensions of learning model. Alexandria, Virginia USA: Association for Supervision and Curriculum Development.

Meltzer D. E. (2002). The Relationship between Mathematics Preparation and Conceptual Learning Gain in Physic: A Possible Hidden Variable in Diagnostic Scores. American Journal Physic, 70 (2), 1259-1267.

Mirhosseini, F. S. (2018). The effectiveness of self-regulation learning skills on motivational and academic variables among students. Middle East Journal Of Family Medicine, 16(5). https://doi.org/10.5742/MEWFM.2018.93385

Ozan, C., Gundogdu, K., \& Bay, E. (2012). -regulated learning strategies skills and selfefficacy perceptions in terms of different variables. Social and Behavioral Sciences, 46(1), 1806-1811. https://doi.org/10.1016/j.sbspro.2012.05.383

Peseta, T., Bell, A., Clifford, A., English, A., Janarthana, J., Jones, C., ... Zhang, J. (2016). Students as ambassadors and researchers of assessment renewal: puzzling over the practices of university and academic life. International Journal for Academic Development, 21(1), 54-66. https://doi.org/10.1080/1360144X.2015.1115406

Purwanto, M. N. (2009). Prinsip-prinsip dan Teknik Evaluasi Pengajaran. Bandung: Remaja Rosdakarya.

Ryerson, R. (2017). Creating possibilities: studying the student experience. Educational Research, 59(3), 297-315. https://doi.org/10.1080/00131881.2017.1343091

Sriyati, S. (2011). Penerapan Asesmen Formatif Untuk Membentuk Habits of mind Mahasiswa Biologi. Sekolah Pascasarjana UPI Bandung. Disertasi. Tidak diterbitkan.

Sugiyono. (2014). Metode Penelitian Kombinasi (Mixed Methods). Bandung. Alfabeta

Vrieling, E., Stijnen, S., \& Bastiaens, T. (2018). Successful learning: balancing self-regulation with instructional planning. Teaching in Higher Education, 23(6), 685-700. https://doi.org/10.1080/13562517.2017.1414784

Wandler, J. B., \& Imbriale, W. J. (2017). Promoting Undergraduate Student Self-Regulation in Online Learning Environments. Online Learning, 21(2), 1-16. https://doi.org/10.24059/olj.v21i2.881

Zimmerman, B. J., \& Schunk, D. H. (2011). Self-regulated performance: An introduction and overview. In B. J. Zimmerman \& D. H. Schunk (Eds.), Handbook of Self-Regulation of Learning and Performance (pp. 1-12). New York, NY: Routledge.

Zimmerman, B. J. (2011). Motivational sources and outcomes of self-regulated learning and performance. In B. J. Zimmerman \& D. H. Schunk (Eds.), Handbook of Self-Regulation of Learning and Performance (pp. 49-64). New York, NY: Routledge. 